\title{
Comparative study between heat pipe and shell-and-tube thermal energy storage
}

\author{
Jose Miguel Maldonado, David Verez, Alvaro de Gracia, Luisa F. Cabeza \\ GREiA Research Group, University of Lleida, Pere de Cabrera s/n, 25001 Lleida, Spain
}

\section{A R T I C L E I N F O}

\section{Keywords:}

Latent heat thermal energy storage (LHTES)

Phase change material (PCM)

Heat pipes

Heat exchanger

Experimental analysis

\begin{abstract}
A B S T R A C T
This paper experimentally evaluates the implementation of heat pipes in latent heat thermal energy storage systems. The well-known performance of heat pipes as a heat transfer technology makes them great candidates to be used as heat exchangers. However, previous studies compared their efficacy against solid metal rods, where heat pipes clearly succeeded. Therefore, the objective of this study is to experimentally evaluate the advantages of using heat pipes instead of a common shell and tubes system, during charging processes. In particular, five latent heat thermal energy storage systems were tested. One based on the shell and tubes, and the remaining four based on heat pipes. The experiments were conducted at constant heat transfer fluid temperature and flow rate, and the results were analysed from the temperature, heat transfer, and visual point of view. The results show that in heat pipes systems the phase change material melts homogeneously through all the storage container. However, the shell and tubes tank performed the charging process in 25 min while the fastest heat pipe one took $40 \mathrm{~min}$ for it. On the other hand, in the shell and tubes configuration melt from the heat transfer fluid inlet towards the outlet. Moreover, systems with more heat pipe surface inside the heat transfer fluid collector provided higher power rates. Comparing the best and the worst heat pipe storage tanks during the first 30 min, the heat transfer rate increased over $40 \%$. But the storing material low conductivity cushioned those high heat transfer rates.
\end{abstract}

\section{Introduction}

Thermal processes can be improved by using thermal energy storage (TES) systems in several ways. They allow to take advantage of waste heat, to work as a thermal shock absorber protecting the device, or to solve the mismatch between the energy supply and demand, the latter helps to integrate renewable energies [1]. Among the different available TES technologies (sensible, latent, and thermochemical), latent heat TES, with phase change materials (PCM), is targeted within this research due to its large energy storage density by means of nearly isothermal processes. However, this technology is limited since the current costeffective PCMs offer low thermal conductivity (fatty acids: $0.15 \mathrm{~W} /$ $\mathrm{m} \cdot \mathrm{K}$; paraffins: $0.20 \mathrm{~W} / \mathrm{m} \cdot \mathrm{K}$; hydrated salts: $0.6 \mathrm{~W} / \mathrm{m} \cdot \mathrm{K}$ ) [2], which hinders the heat transfer during both loading and unloading processes.

Many studies were focused in different enhancement techniques to increase the heat transfer rate in TES systems [3-5], such as the addition of fins, bubble agitation, embedding metal matrixes, metal foams $[6,7]$, or other materials (graphite or nano-particles) into the PCM, and inserting heat pipes [8-10]. Enlarging the heat transfer surface is one of the easiest ways to increase the heat transfer rate to and from the storage tank, by adding fins or enlarging the pipe surface, through where the heat transfer fluid flows, for instance adding more coils into the tank. However, larger piping network increases pressure drops and it decreases the effective PCM storage volume. The replacement of the piping network by heat pipes in the TES tank avoids one of those issues, since more heat pipes can be added without affecting the heat transfer fluid (HTF) flow and therefore without increasing the pumping cost. With a minimal temperature difference as driving force, heat pipes can passively and almost isothermally transport great amounts of heat $[11,12]$. Heat pipes can be several thousand times as effective as the best metals in heat transporting [13], making them a pursued choice to enhance the already mentioned PCM low heat conductivity [14]. Fins addition in PCM TES tanks was studied in deep by many researchers, providing high heat transfer rates. Lacroix and Benmadda [15] conducted a numerical study of the melting and solidification process of a PCM from a vertical wall, short and long fins were attached to the wall. They found that is better to add a few long fins than several short ones.

\footnotetext{
Abbreviations: TES, Thermal energy storage; PCM, Phase change material; HTF, Heat transfer fluid; HP, Heat pipe.

* Corresponding author.

E-mail address: luisaf.cabeza@udl.cat (L.F. Cabeza).
} 


\begin{tabular}{|c|c|}
\hline \multicolumn{2}{|c|}{ Nomenclature } \\
\hline $\mathrm{C}_{\mathrm{p}}$ & Specific heat, $\mathrm{J} / \mathrm{kg} \cdot{ }^{\circ} \mathrm{C}$ \\
\hline$\Delta \mathrm{T}$ & Temperature difference, ${ }^{\circ} \mathrm{C}$ \\
\hline HP & Heat pipe \\
\hline IN & Inlet \\
\hline OUT & Outlet \\
\hline $\mathrm{P}$ & Heat transfer rate, $\mathrm{W}$ \\
\hline $\mathrm{R}$ & $\mathrm{R}$ is a given function of the independent variables \\
\hline $\mathrm{t}$ & Time, s \\
\hline $\mathrm{T}$ & Temperature, ${ }^{\circ} \mathrm{C}$ \\
\hline v & Flow rate, $\mathrm{m}^{3} / \mathrm{s}$ \\
\hline $\mathrm{w}$ & $\begin{array}{l}\text { Uncertainties which are associated to the independent } \\
\text { parameters }\end{array}$ \\
\hline $\mathrm{W}$ & $\begin{array}{l}\text { Estimated uncertainty in the final result, value- } \\
\text { dependent }\end{array}$ \\
\hline $\mathrm{x}$ & Independent measured parameters \\
\hline \multicolumn{2}{|c|}{ Greek symbols } \\
\hline$\rho$ & Density, $\mathrm{kg} / \mathrm{m}^{3}$ \\
\hline
\end{tabular}

Seeniraj et al. [16], Gharebaghi and Sezai [17] performed a numerical study of a latent TES system with fins,. Both studies performed a parametric analysis regarding the fins geometry and the number of fins, reflecting that by increasing these parameters, consequently the heat transfer did it too, obtaining higher heat transfer rates. Hoseeinizadeh et al. [18] experimentally and numerically studied a latent TES performance with different fins geometries too, concluding that increasing the fin thickness showed a slight improvement. Guo and Zhang [19] also carried out a numerical study regarding the use of fins in latent heat TES, determining that including them, the solidification process increased significantly. Similar study was performed by Tae and He [20], but they found the optimum configuration regarding fins number, thickness, and height, for a given TES geometry. All in all, the use of fins increases the heat transfer rate between the PCM and the heat carrier. Nevertheless, fins were out of the scope of the current study, since the authors focused on evaluate the heat pipe potentialities as a better heat exchanger than traditional shell and tubes configuration. The heat pipe behaviour in a real latent heat TES tanks was deeply assessed though difference experimental tests.

Many researchers studied experimentally and numerically the use of heat pipes in latent heat TES systems. Faghri et al. [21-24] designed a cylindrical latent heat TES coupled with heat pipes, in which they compared a copper rod against a heat pipe, both with and without fins attached. Every heat pipe configuration, just heat pipe, heat pipe plus foil, and heat pipe with foam, enhanced the melting time in regards to the reference scenario, by $37 \%, 93.5 \%$, and $89.5 \%$, respectively. Same design was used by Motahar et al. [25] (cylindrical latent TES assisted with a heat pipe) with n-octadecane as PCM, to test the effect of inlet temperature. The charging time was reduced by $53 \%$ when the inlet temperature was raised from $35{ }^{\circ} \mathrm{C}$ to $50{ }^{\circ} \mathrm{C}$. The use of heat pipes has been also numerically studied [26-32]. Tiari et al. developed a transient 2-D high temperature squared PCM tank [26], first with just fins and later on adding nanoparticles [28]. Also, they modelled a PCM cylindrical finned tank in 3-D [27]. These studies analysed the influence of heat pipes number, and their location along the PCM tank. They concluded that more heat pipes increased the melting rate, also that an optimum heat pipe distribution could enhance the system performance. Regarding the addition of nanoparticles, their study showed that higher nanoparticles volume fraction, resulted in faster charging processes. Pan et al. developed also a circular finned PCM tank model, but this time the study was focussed into minimizing the cost $[29,30]$. They reflected that thinner fins, offered cheaper systems. Also, the realized that if the fins were thicker than $2 \mathrm{~mm}$, it was smarter to add more heat pipes than weld those fins. Lohrasbi et al. modelled a similar system but with different fins geometries $[31,32]$. The studies showed that as the fins attached to the heat pipes grew longer and thicker the discharging rate improved. None of these studies compared the heat pipes against a HTF flowing through pipes, just against solid copper rods.

From the literature review, it can be stated that replacing metal rods by heat pipes is a suitable solution to enhance the heat transfer in latent heat TES systems. However, this comparison is not very useful since many heat transfer systems usually consist in a piping network where the HTF flows. Therefore, unlike previous studies this study experimentally compares the heat pipes against those conventional systems with HTF. By doing this comparison, the strengths of both heat transfer techniques could be spotted, leading the way for future research. Since heat pipes are passive systems, their implementation could save pumping power, and mechanical complexity within the storage system, implying energy and economical savings. For that purpose, a latent heat TES tank with heat pipes was designed and built to assess the advantages and drawbacks over a conventional shell and tubes TES tank. The tank designs were done considering the packing factor and system compactness. Loading processes were evaluated regarding the temperature, power and process time. The study showed that the heat pipes by themselves did not stand out over a conventional HTF heat transfer system in every aspect. Although they did offer some advantages which can be really useful regarding the final application and its requirements.

\section{Methodology}

\subsection{Materials}

The PCM selected in this experimentation is n-octadecane (technical grade, $90 \%$ purity), supplied by Alfa Aesar, Germany. The main thermophysical properties of this material are shown in Table 1.

Water is the HTF used in this experimentation, therefore, the thermophysical properties utilized for the evaluation are summarized in Table 2.

\subsection{Experimental set-up}

The experimentation performed in the present paper was carried out at the laboratory of the GREiA research group at the University of Lleida in Spain, in a set-up designed to characterize and test latent heat TES systems for mid-low temperature applications $\left(-20^{\circ} \mathrm{C}<\mathrm{T}<100{ }^{\circ} \mathrm{C}\right)$. Fig. 1 shows a detailed schematic view of this experimental set-up. It is composed of a $25 \mathrm{~L}$ inertia storage tank, the temperature of which is controlled by a vapour compression cooling unit (Zanotti model GCU2030ED01B) with $4.956 \mathrm{~kW}$, and two immersion thermostats (OVAN TH100E-2 kW and JP SELECTA-1 kW). This water/glycol tank is heated up for performing the charging process, and then cool down before starting the discharging. Then the water/glycol flows through a heat exchanger with the HTF used in the storage tanks. That way, the HTF flow circuit is always the same for both charging and discharging. The set-up also integrates two variable speed pumps, used to control the

Table 1

Thermophysical properties of n-octadecane [33,34].

\begin{tabular}{ll}
\hline Properties & Value \\
\hline Chemical formula & $\mathrm{CH}_{3}\left(\mathrm{CH}_{2}\right)_{16} \mathrm{CH}_{3}$ \\
Melting temperature & $27.7{ }^{\circ} \mathrm{C}$ \\
Latent heat & $243.5 \mathrm{~J} / \mathrm{g}$ \\
Specific heat capacity (solid) & $2.14 \mathrm{~kJ} / \mathrm{kg} \cdot \mathrm{K}$ \\
Specific heat capacity (liquid) & $2.66 \mathrm{~kJ} / \mathrm{kg} \cdot \mathrm{K}$ \\
Density (solid) & $865 \mathrm{~kg} / \mathrm{m}^{3}$ \\
Density (liquid) & $785 \mathrm{~kg} / \mathrm{m}^{3}$ \\
Thermal conductivity (solid) & $0.190 \mathrm{~W} / \mathrm{m} \cdot \mathrm{K}$ \\
Thermal conductivity (liquid) & $0.148 \mathrm{~W} / \mathrm{m} \cdot \mathrm{K}$ \\
\hline
\end{tabular}


Table 2

Thermophysical properties of pure water at atmospheric pressure [35].

\begin{tabular}{lll}
\hline Properties & at $15{ }^{\circ} \mathrm{C}$ & at $45{ }^{\circ} \mathrm{C}$ \\
\hline Density & $999.1 \mathrm{~kg} / \mathrm{m}^{3}$ & $992.2 \mathrm{~kg} / \mathrm{m}^{3}$ \\
Dynamic viscosity & $1.136 \cdot 10^{3} \mathrm{~N} \cdot \mathrm{s} / \mathrm{m}^{2}$ & $0.652 \cdot 10^{3} \mathrm{~N} \cdot \mathrm{s} / \mathrm{m}^{2}$ \\
Thermal conductivity & $0.595 \mathrm{~W} / \mathrm{m} \cdot \mathrm{K}$ & $0.653 \mathrm{~W} / \mathrm{m} \cdot \mathrm{K}$ \\
Thermal expansion coefficient & $15.073 \cdot 10^{5} 1 / \mathrm{K}$ & $38.530 \cdot 10^{5} 1 / \mathrm{K}$ \\
Specific heat & $4.19 \mathrm{~kJ} / \mathrm{kg} \cdot \mathrm{K}$ & $4.18 \mathrm{~kJ} / \mathrm{kg} \cdot \mathrm{K}$ \\
\hline
\end{tabular}

flow and inlet temperature at the TES system; a flow meter Badger meter type ModMAG M1000, with an accuracy of $\pm 0.3 \%$ of the actual flow, and the latent heat TES system. The connections between components are done with 0.5 in. copper HTF pipes, which are insulated with $18 \times 0.9$ $\mathrm{mm}$ polyurethane tubes. The data acquisition system, consist in 3 STEP DL-01 data logger, connected to a computer with a system control and data acquisition software (SCADA), developed in InduSoft Web Studio for the set-up.

Five different latent heat TES systems were tested in the experimental set-up, one based on the shell-and-tube heat exchanger concept (ST: Fig. 2a) used as control, and the remaining four based on heat pipes concept (Fig. 2b, c, d, and e). Unlike the shell and tubes latent heat TES, those which included heat pipes required a manifold where HTF and heat pipes exchange heat. The heat pipes used were made in copper, with sintered metal wick, capillary driven, water as inner working fluid and $350 \mathrm{~mm}$ in length. Two of the heat pipes latent TES tanks (HP16_A and HP16_B: Fig. 2b and c) were built with ten heat pipes of $16 \mathrm{~mm}$ diameter each, matching the diameter of the copper tubes used before in the shell and tubes tank configuration. Therefore, same packing factor (ratio between the PCM volume and the storage tank volume) and heat transfer surface was achieved but with heat pipes. The remaining two heat pipes latent TES tanks (HP10_A and HP10_B: Fig. 2d and e) were built with ten heat pipes of $10 \mathrm{~mm}$ diameter each, to analyse the influence of the diameter of the HP in the process studied. And to characterize the heat pipes TES tank even with a higher packing factor and a lower heat transfer surface than shell and tubes tank configuration. A and $B$ configurations differed in the heat pipe length introduced into the HTF manifold, being longer at B ones. Consequently, the PCM vessel in HP16_B and HP10_B was reduced, keeping the same packing factor as their homologs. Table 3 summarizes the main characteristics of the five latent heat TES systems. Each latent heat TES tank was insulated with $80 \mathrm{~mm}$ thick polystyrene sheets. The average thermal losses of the systems to the ambient were $2.5 \mathrm{~W}$.

The temperature of the PCM placed inside the heat exchangers was measured with eight Pt-100 class B, IEC 60,751 standard type, with accuracy of $\pm 0.3^{\circ} \mathrm{C}$. These temperature sensors were located as shown in Fig. 3, at a distance of $40 \mathrm{~mm}$ from the bottom of the heat exchanger. In addition, two additional Pt-100 1/5 DIN class B temperature sensors with an accuracy of $\pm 0.3{ }^{\circ} \mathrm{C}$ were located at the inlet and outlet of the heat exchangers HTF tubes for ST, and at the inlet and the outlet of the HTF manifold for the heat pipes TES tanks. Also, the processes were video recorded with a full HD webcam USB 2.0, model BIOFUN Webcam 1080P. The camera was placed directly above the latent heat TES tank (Fig. 4).

The present experimentation consisted of performing in each TES system several charging and discharging processes at a constant flow rate of $0.05 \pm 0.002 \mathrm{~kg} / \mathrm{s}$. To perform a loading process, the tank was cooled down until all sensors in direct contact with the PCM were set to $15 \pm 1{ }^{\circ} \mathrm{C}$. Later the HTF inlet temperature was set at $45 \pm 1{ }^{\circ} \mathrm{C}$. The charge was considered finished when all sensors embedded in the PCM where at least at $30^{\circ} \mathrm{C}$. To proceed with the discharge, the TES tank was heated up to $40 \pm 1{ }^{\circ} \mathrm{C}$, the HTF inlet set at $15 \pm 1{ }^{\circ} \mathrm{C}$, and the discharge was considered done when all temperature sensors were below $20^{\circ} \mathrm{C}$.

\subsection{Uncertainties analysis}

The impact of the different measured parameter uncertainties on the calculated values was evaluated by performing an uncertainty analysis. This analysis was needed to validate the study. The uncertainties of the different monitored parameters are shown in Table 4. HTF specific heat and density were calculated following the correlations presented in Eq.1 and Eq. (2) [35], and the heat transfer rate with Eq. (3):

$$
\begin{aligned}
& \rho_{H T F}=1.38 e^{-5} \cdot T_{H T F}^{2}-5.63 e^{-3} \cdot T_{H T F}^{2}+3.6 e^{-3} \cdot T_{H T F}^{2}+1000 \\
& C p_{H T F}=2.69 e^{-9} \cdot T_{H T F}^{4}-6.63 e^{-7} \cdot T_{H T F}^{3}+6.67 e^{-5} \cdot T_{H T F}^{2}-2.67 e^{-3} \cdot T_{H T F}^{1}+4.21
\end{aligned}
$$

$Q_{H T F}=C p_{H T F} \cdot\left(\rho_{H T F} \cdot \dot{v}_{H T F}\right) \cdot \Delta T_{H T F}$

By applying Eq. (4) to the different parameters [36], the uncertainties of the HTF thermophysical properties (density and specific heat) as well as of the heat transfer rates were estimated. The uncertainty was estimated at each registered time step, and then the mean value was used. Table 5 shows the average uncertainties of the HTF density specific heat, and power during the different processes carried out.

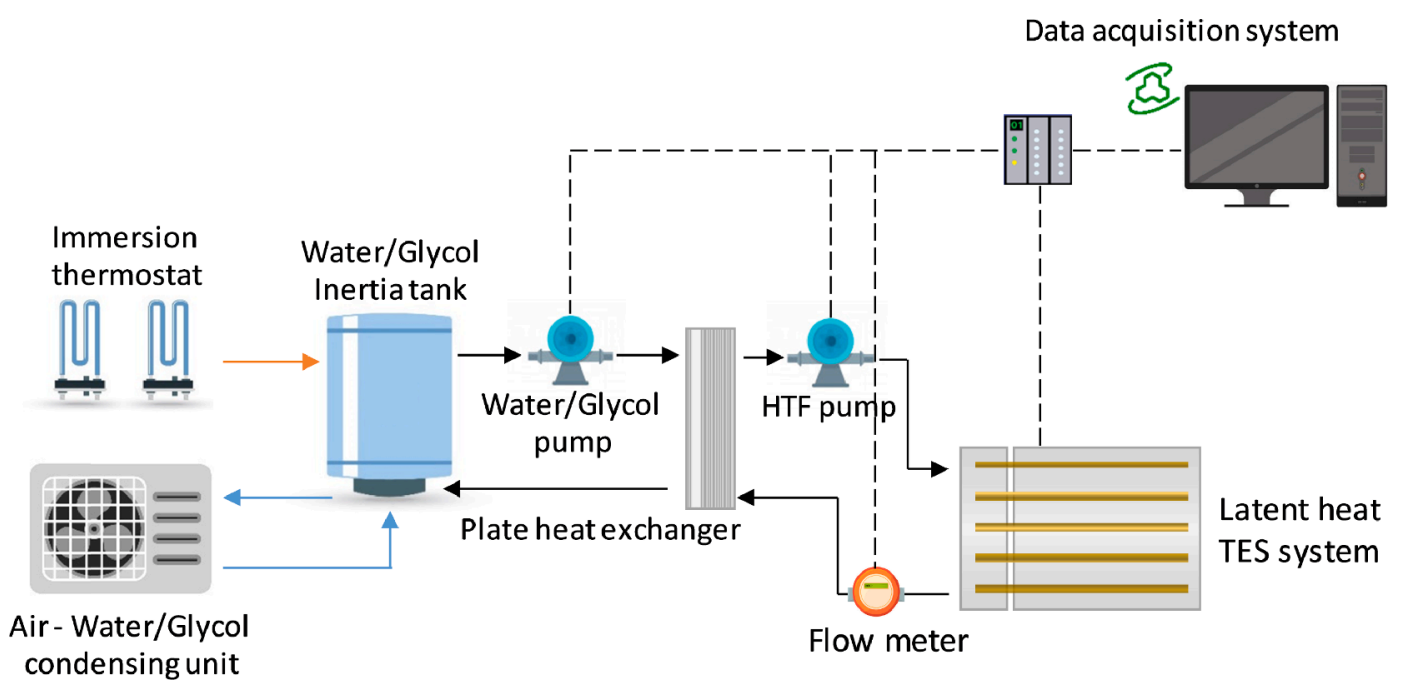

Fig. 1. Schematic view of the experimental set-up usJose Migueled to perform the experimentation. 


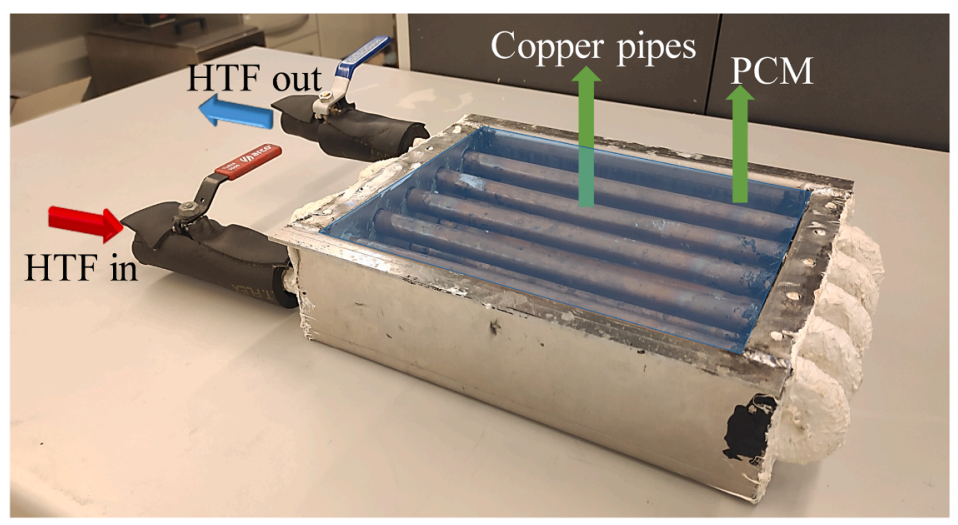

(a)

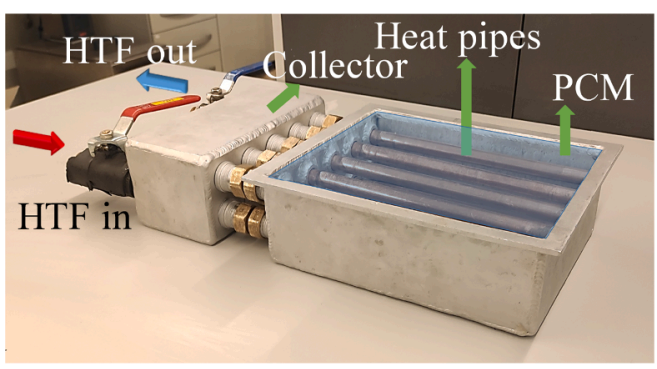

(b)

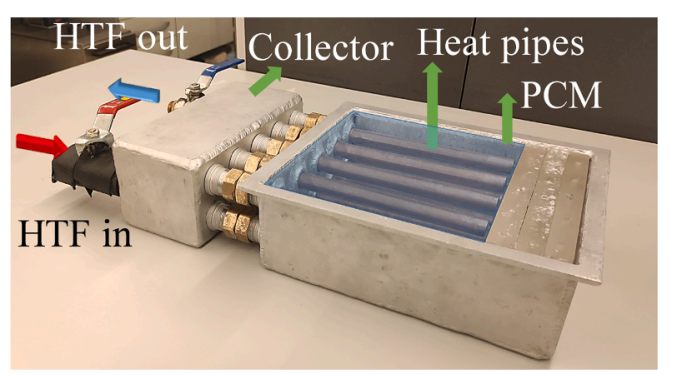

(d)

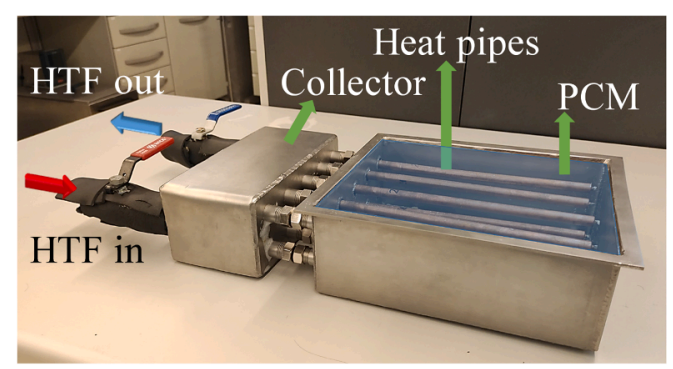

(c)

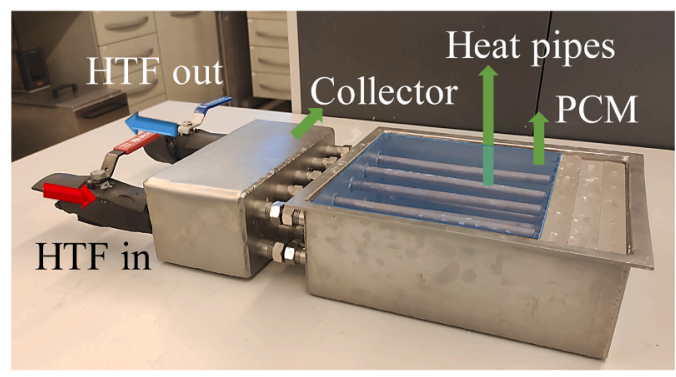

(e)

Fig. 2. Schematic overview and actual pictures of the different latent heat exchangers tested in the present study: (a) ST: Shell and tubes; (b) HP16_A: 16 mm Heat pipes; (c) HP10_A: $10 \mathrm{~mm}$ Heat pipes; (d) HP16_B: $16 \mathrm{~mm}$ Heat pipes; (e) HP10_B: $10 \mathrm{~mm}$ Heat pipes.

Table 3

Characteristics of the latent heat TES systems analysed and presented in this paper.

\begin{tabular}{clllll}
\hline & ST & HP16_A & HP10_A & HP16_B & HP10_B \\
\hline Dimensions & $360 \times$ & $360 \times 85$ & $360 \times 85$ & $360 \times$ & $360 \times$ \\
$\quad$ length $\times$ & $85 \times$ & $\times 210$ & $\times 210$ & $85 \times$ & $85 \times$ \\
depth $\times$ width) & $210 \mathrm{~mm}$ & $\mathrm{~mm}$ & $\mathrm{~mm}$ & $210 \mathrm{~mm}$ & $210 \mathrm{~mm}$ \\
PCM storage & $250 \times$ & $250 \times 85$ & $250 \times 85$ & $185 \times$ & $185 \times$ \\
dimensions & $85 \times$ & $\times 210$ & $\times 210$ & $85 \times$ & $85 \times$ \\
$\quad$ length $\times$ & $210 \mathrm{~mm}$ & $\mathrm{~mm}$ & $\mathrm{~mm}$ & $210 \mathrm{~mm}$ & $210 \mathrm{~mm}$ \\
depth $\times$ width) & & & & & \\
Pipe material & Copper & Copper & Copper & Copper & Copper \\
Pipe diameter & $16 \mathrm{~mm}$ & $16 \mathrm{~mm}$ & $10 \mathrm{~mm}$ & $16 \mathrm{~mm}$ & $10 \mathrm{~mm}$ \\
Type of heat & Shell and & Heat & Heat & Heat & Heat \\
exchange & tubes & Pipes & Pipes & Pipes & Pipes \\
system & & & & & \\
Packing factor & 0.703 & 0.718 & 0.897 & 0.720 & 0.836 \\
Heat transfer & $1.25 \mathrm{e}-02$ & $1.46 \mathrm{e}-02$ & $8.64 \mathrm{e}-03$ & $1.16 \mathrm{e}-02$ & $6.75 \mathrm{e}-03$ \\
area & $\mathrm{m}^{2}$ & $\mathrm{~m}^{2}$ & $\mathrm{~m}^{2}$ & $\mathrm{~m}^{2}$ & $\mathrm{~m}^{2}$ \\
PCM mass & 2453.9 & 2505.6 & 2720.0 & 1910.4 & 1994.8 \\
& $\pm 0.5 \mathrm{~g}$ & $\pm 0.5 \mathrm{~g}$ & $\pm 0.5 \mathrm{~g}$ & $\pm 0.5 \mathrm{~g}$ & $\pm 0.5 \mathrm{~g}$ \\
\hline
\end{tabular}

$W_{R}=\left[\left(\frac{\partial R}{\partial x_{1}} \cdot w_{x_{1}}\right)^{2}+\left(\frac{\partial R}{\partial x_{2}} \cdot w_{x_{2}}\right)^{2}+\cdots+\left(\frac{\partial R}{\partial x_{n}} \cdot w_{x_{n}}\right)^{2}\right]^{1 / 2}$

being $W_{R}$ the estimated uncertainty in the final result, $R$ the function which depends on the measured parameters, $x_{n}$ are the different independent monitored parameters, and $\mathrm{w}_{\mathrm{x}}$ are the uncertainties associated to those independent parameters.

\subsection{Repeatability}

Along this study the different experiments were repeated three times following the same operating and boundary conditions, ensuring repeatability of results. Fig. 5 shows the mean HTF inlet, HTF outlet, and eight PCM temperatures, of the three repeated tests performed with the ST latent heat TES tank, as well as their standard deviations. The maximum standard deviations regarding the HTF inlet and outlet temperatures (T_HTF_inlet and T_HTF_outlet) were $0.97{ }^{\circ} \mathrm{C}$ over $21.94{ }^{\circ} \mathrm{C}$, and $1.02{ }^{\circ} \mathrm{C}$ over $19.13^{\circ} \mathrm{C}$. The maximum standard deviation found within the PCM Pt-100 was $2{ }^{\circ} \mathrm{C}$ over $28.97{ }^{\circ} \mathrm{C}$ during the charge (T7_mean). However, the deviation dropped to values lower than $1{ }^{\circ} \mathrm{C}$ in less than one minute. Within the others sensors the deviation behaved 


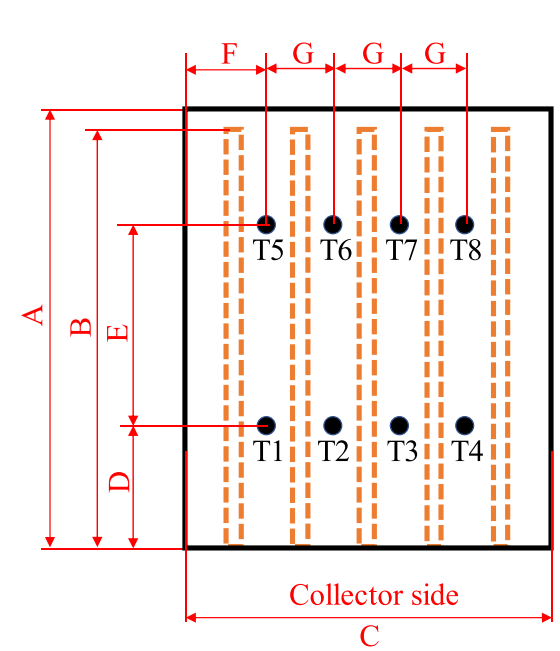

\begin{tabular}{|c|c|c|c|c|c|c|c|}
\hline $\begin{array}{c}\text { Storage } \\
\text { tank }\end{array}$ & A & B & C & D & E & F & G \\
\hline ST & 250 & 250 & 210 & 40 & 160 & 60 & 40 \\
\hline HP16_A & 250 & 230 & 210 & 40 & 160 & 60 & 40 \\
\hline HP10_A & 250 & 230 & 210 & 40 & 160 & 60 & 40 \\
\hline HP16_B & 185 & 180 & 210 & 20 & 160 & 60 & 40 \\
\hline HP10_B & 185 & 180 & 210 & 20 & 160 & 60 & 40 \\
\hline
\end{tabular}

Fig. 3. PCM temperature sensors location (dimensions in $\mathrm{mm}$ ).

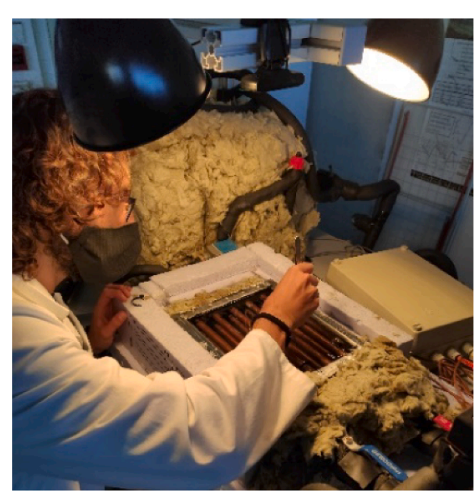

(a)

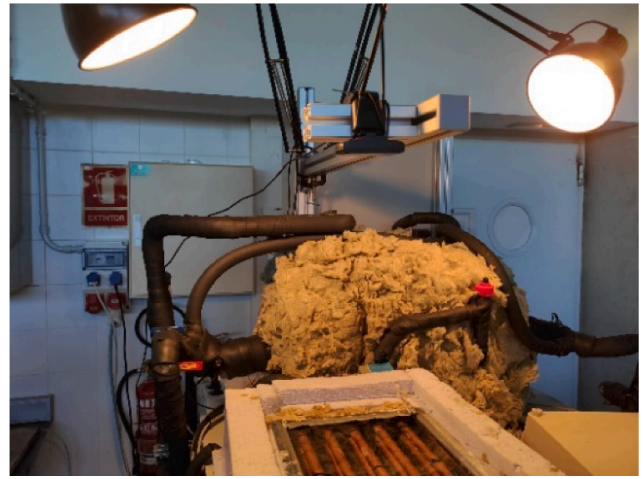

(b)

Fig. 4. Experimental set up: (a) thermocouples placement; (b) video recording set-up.

Table 4

Uncertainties of the different parameters involved in the analyses of the present study.

\begin{tabular}{llll}
\hline Parameter & Units & Sensor & Accuracy \\
\hline Temperature & ${ }^{\circ} \mathrm{C}$ & Pt-100 1/5 DIN class B & \pm 0.3 \\
Flow rate & $1 / \mathrm{min}$ & Badger meter type ModMAG M1000 & $\pm 0.3 \%$ \\
\hline
\end{tabular}

Table 5

Estimated uncertainties of the HTF thermophysical properties and power.

\begin{tabular}{|c|c|c|c|c|c|c|}
\hline \multirow{2}{*}{$\begin{array}{l}\text { Storage } \\
\text { tank }\end{array}$} & \multicolumn{2}{|l|}{ Density } & \multicolumn{2}{|c|}{ Specific heat } & \multicolumn{2}{|c|}{ Heat transfer rate } \\
\hline & $\begin{array}{l}{[ \pm \mathrm{kg} /} \\
\left.\mathrm{m}^{3}\right]\end{array}$ & {$[ \pm \%]$} & $\begin{array}{l}{[ \pm \mathrm{kJ} /} \\
\left.\mathrm{kg} \cdot{ }^{\circ} \mathrm{C}\right]\end{array}$ & {$[ \pm \%]$} & {$[ \pm \mathrm{kW}]$} & $\begin{array}{l}{[ \pm} \\
\%]\end{array}$ \\
\hline \multirow[t]{2}{*}{ ST } & 2.96 & 2.99 & \multirow[t]{2}{*}{$1.87 \mathrm{e}-5$} & 4.48 & 2.35 & \multirow[t]{2}{*}{7.64} \\
\hline & $e-2$ & $e-3$ & & $e-4$ & $e-2$ & \\
\hline \multirow[t]{2}{*}{ HP16_A } & 2.97 & $3 e-3$ & \multirow[t]{2}{*}{$1.91 \mathrm{e}-5$} & 4.57 & 2.36 & \multirow[t]{2}{*}{9.17} \\
\hline & $e-2$ & & & $e-4$ & $e-2$ & \\
\hline \multirow[t]{2}{*}{ HP10_A } & 3.09 & 3.12 & \multirow[t]{2}{*}{$2.06 \mathrm{e}-5$} & 4.93 & 2.39 & \multirow[t]{2}{*}{13.9} \\
\hline & $e-2$ & $e-3$ & & $e-4$ & $e-2$ & \\
\hline \multirow[t]{2}{*}{ HP16_B } & 2.92 & 2.94 & \multirow[t]{2}{*}{$1.86 \mathrm{e}-5$} & 4.46 & 2.34 & \multirow[t]{2}{*}{9.02} \\
\hline & $e-2$ & $e-3$ & & $e-4$ & $\mathrm{e}-2$ & \\
\hline \multirow[t]{2}{*}{ HP10_B } & \multirow[t]{2}{*}{$3 e-2$} & 3.03 & \multirow[t]{2}{*}{$1.94 \mathrm{e}-5$} & 4.63 & 2.36 & \multirow[t]{2}{*}{10.1} \\
\hline & & $e-3$ & & $\mathrm{e}-4$ & $e-2$ & \\
\hline
\end{tabular}

similarly, being almost at every time below $1^{\circ} \mathrm{C}$.

\section{Results and discussion}

\subsection{Temperature evaluation}

Fig. 6 shows the PCM mean temperature in the five different TES tanks. In the chart it can be seen that the fastest system was the ST which completed the charging process in $25.7 \mathrm{~min}$; then the $16 \mathrm{~mm}$ heat pipe systems, HP16_B and HP16_A in 40.3 and 53.1 min respectively. The last ones were the $10 \mathrm{~mm}$ heat pipes HP10_B and HP10_A tanks, finishing at 72 and $77 \mathrm{~min}$, respectively (Fig. 6). When comparing HP16_A versus HP10_A, the second took 24 min longer, but 200 additional PCM grams were stuffed into the HP10_A TES tank due to the heat pipes diameter difference, supplying 52 additional kJ. Also, the heat pipes heat transfer surface was reduced over $60 \%$. Both facts, made heat conduction within the PCM to have a greater impact in the process. To better understand how decisive was the surface reduction in the process, Section 3.2 analyses the heat transfer rate per heat pipe surface area. It has to be pointed out that the ST tank showed the highest standard deviation (being $3.29^{\circ} \mathrm{C}$ ). The reason lies in how the PCM front melting evolved, following the HTF flowing. The process went laterally from the HTF inlet towards the HTF outlet, so the difference between the temperature sensors were higher than when using heat pipes. This behaviour was corroborated later by filming the melting process.

To analyse the relevance of the heat transfer between the HTF and 


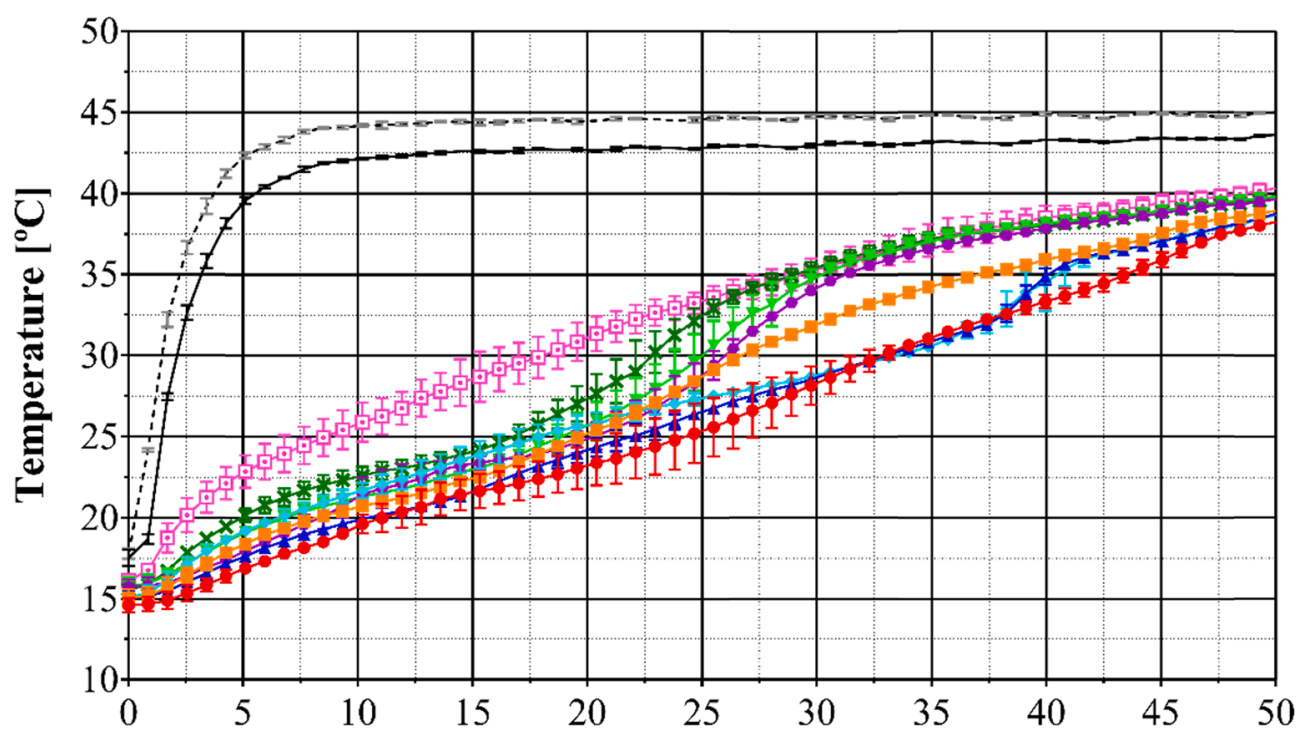

Time [min]

Fig. 5. HTF and PCM mean plus standard deviation profiles for reference latent heat TES system.

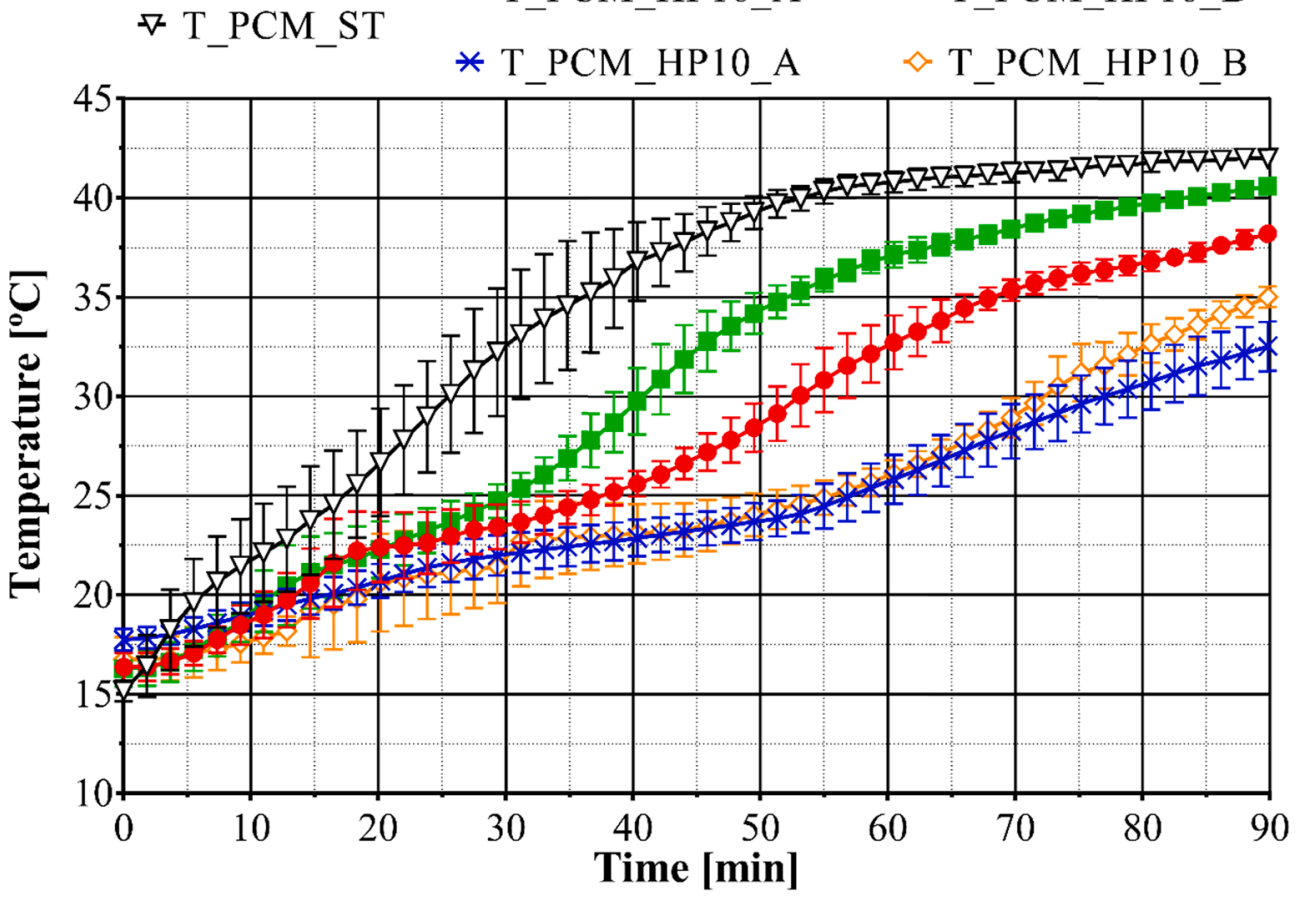

Fig. 6. PCM mean temperature comparison among the five different latent heat TES systems during the charging process.

the heat pipes, as aforementioned, a secondary heat pipe configuration was designed and tested (HP16_B and HP10_B). B configuration enlarged the heat pipe length inside the HTF manifold, but the PCM tank had to be shortened to use the same heat pipes (same properties). B configuration heat pipes had higher surface in contact with the HTF, keeping the same packing factor as configuration A, but the PCM volume was reduced. By increasing the heat transfer surface inside the manifold by a $36.36 \%$, HP16_B enhanced HP16_A, achieving the loading process $12.8 \mathrm{~min}$ faster $(24.11 \%)$. On the other hand, this change in configuration regarding surface of heat pipes inside the manifold has less impact in case of using thinner heat pipes, as HP10_B only responded $7 \mathrm{~min}$ faster (6.49\%) than HP10_A (Fig. 7). So, regarding the melting process time, inserting the heat pipes deeper into the HTF manifold had better results with the $16 \mathrm{~mm}$ heat pipes. When comparing HP16_B and HP10_B, Fig. 6 shows that thinner heat pipes took $24 \mathrm{~min}(78.66 \%)$ longer. As stated above, this happens because of the extra PCM and the $60 \%$ lower heat pipe heat transfer surface. This analysis is complemented by the heat transfer rate assessment.

Fig. 7 plots the PCM temperature profiles of every sensor during the experiments with the different latent heat TES tanks. It has to be pointed out that the time difference between the fastest and slowest temperature sensors to reach $30^{\circ} \mathrm{C}$ was $18.6 \mathrm{~min}$ when using the ST tank. Higher than all the differences registered in the heat pipe tanks; which were 12.5, $10.5,11$, and $8 \mathrm{~min}$ when loading HP16_A, HP16_B, HP10_A, and 


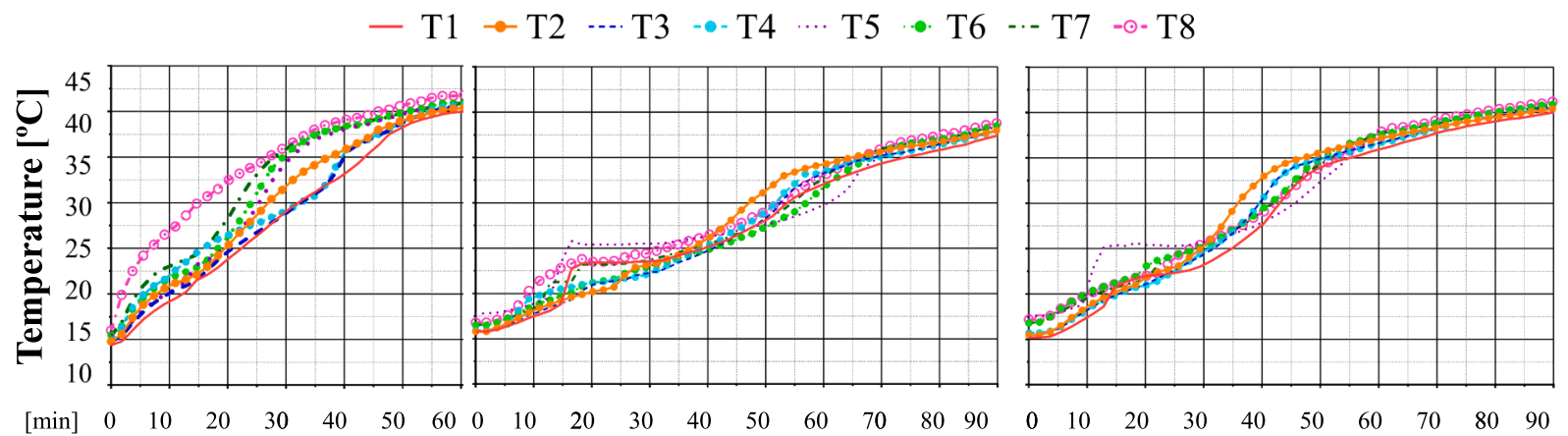

(a) Shell and tubes

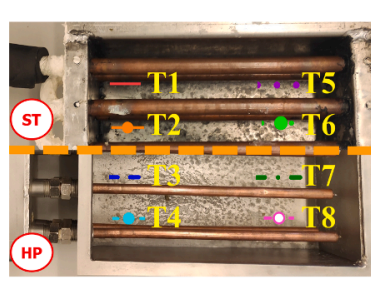

(f) Temperature sensor

distribution in TES tank (b) Heat pipes $16 \mathrm{~mm} \mathrm{~A}$

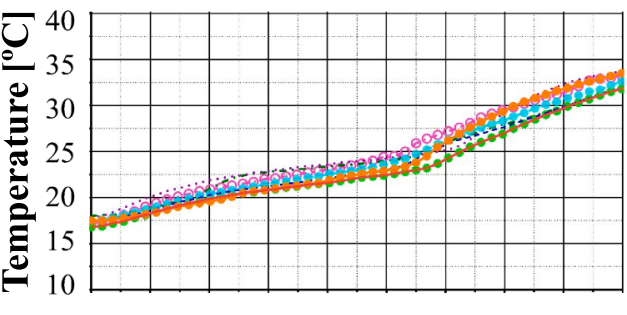

$\begin{array}{lllllllllll}{[\min ]} & 0 & 10 & 20 & 30 & 40 & 50 & 60 & 70 & 80 & 90\end{array}$

(d) Heat pipes $10 \mathrm{~mm} \mathrm{~A}$ (c) Heat pipes $16 \mathrm{~mm} \mathrm{~B}$

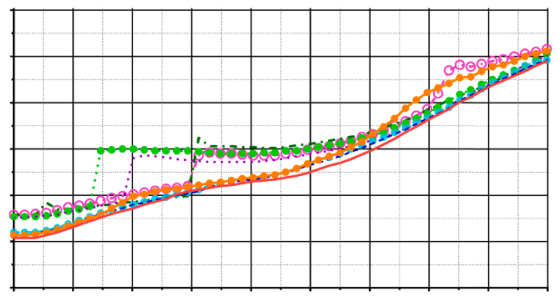

(e) Heat pipes $10 \mathrm{~mm} \mathrm{~B}$

Fig. 7. PCM temperature profiles in the different latent heat TES tanks: (a) ST; (b) HP16_A; (c) HP16_B; (d) HP10_A; (e) and HP10_B. (f) Sensors distribution along the PCM tank.

HP10_B tanks, respectively (Fig. 7). This dispersion on the temperature shows that the charging process happened in the heat pipe systems more homogeneously. The reason lies in how the PCM melting front evolved in the ST tank following the HTF flow direction. The process went laterally from the HTF inlet region towards the HTF outlet, so the difference between the temperature sensors were higher than when using heat pipes. From the temperature results it could be seen that the phase change happened uniformly while using heat pipes. This homogeneous phase changing is useful to avoid hot zones, which could overheat the system, especially in high temperature applications. This behaviour was corroborated later by filming the melting process (Section 3.3. Visual analysis). The temperature gradient along the PCM pushes forward the melting process, since the natural convection mechanism is boosted. This effect, which benefits the ST latent TES tank, is hampered when implementing fins in the tank. Therefore, presumably the fin addition would have a greater impact if coupled with heat pipes. It has to be mentioned that sometimes solid PCM gets stuck to the temperature sensors, and when it drops the sensor reading shows a rapid increase as seen in Fig. $7 \mathrm{~b}$, c, and e.

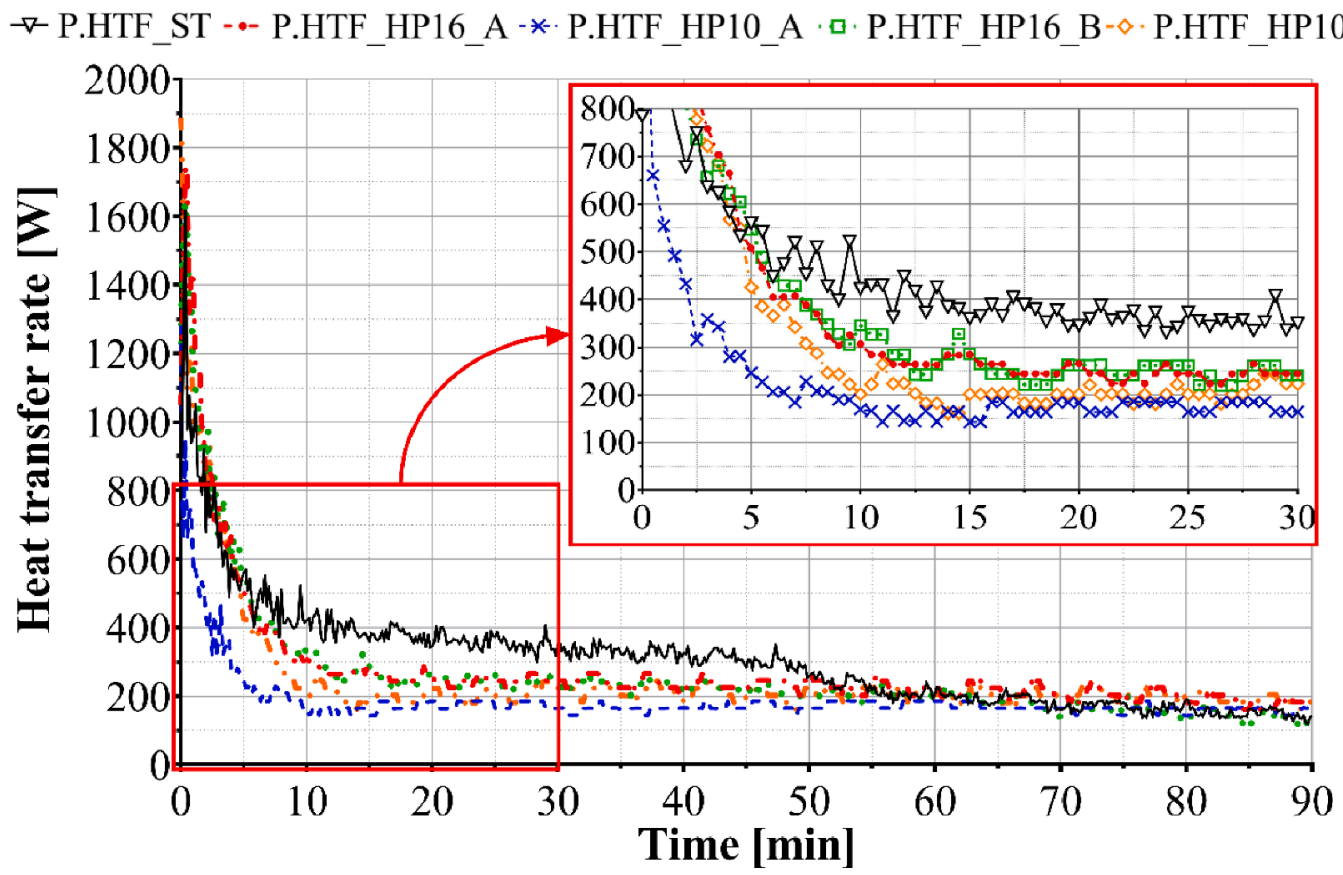

Fig. 8. Heat transfer rate comparison between the four different latent heat TES systems during the charging process. 


\subsection{Heat transfer rate comparison}

The heat transfer rate was calculated with the HTF inlet and outlet temperatures (Eq. (3)). Fig. 8 show the comparison in terms of power among the five different latent heat TES systems. ST latent TES showed higher heat transfer rate along almost the whole process. In the first 5 min HP16_A, HP16_B, and HP10_B achieved higher peak values, but falling down below ST heat transfer rate during the rest of the experiment. The power supplied by HP16_A, HP16_B, and HP10_B got muffled once the PCM around the heat pipes starts to rise its temperature (due to the low PCM thermal conductivity). As heat pipe required temperature gradient between tips $\left(\Delta \mathrm{T}_{\mathrm{HP}}\right)$ to work; if the temperature of PCM around them keeps rising, because the heat conductivity along the PCM is very low, $\Delta \mathrm{T}_{\mathrm{HP}}$ decreases. Lower $\Delta \mathrm{T}_{\mathrm{HP}}$ means lower heat pipes power rates because the heat pipe working fluid mass flow is hampered, and consequently its heat transfer rate. The latter effect does not affect the ST tank, since the HTF mass flow is pumped.

HP10_A showed the worst performance of all tanks (Fig. 8). By analysing it versus HP16_A and HP10_B, the results show two main parameters affecting the performance of HP10_A. The diameter of the heat pipe, and the length inside the HTF collector, which define the heat transfer surface of the heat pipe. Therefore, not only $\Delta \mathrm{T}_{\mathrm{HP}}$ is relevant to make the heat pipe wok, but also enough heat transfer surface along in the heat pipe evaporator section is required. Otherwise, the heat pipe circuit may not even start, or reduce its performance. Those parameters constrain the HTF collector design.

To analyse the influence of the heat pipes diameter, the power ratio per heat transfer surface area was plotted in Fig. 9. The chart presents that regarding the heat transfer rate per heat pipe area, HP10_B achieved the best performance among all systems. Since, HP10_B maintained higher rates throughout the charging process, also it reached two times the peak power of HP16_B, and two and a half times the peak power of ST. Moreover, HP16_A and HP16_B performed similarly, while HP10_A maintained the worst results. The results suggest that, in terms of power, it would be better to have the same heat transfer surface as HP16_B configuration, but adding more $10 \mathrm{~mm}$ heat pipes. That way, the gap among heat pipes in the PCM tank would be reduced, avoiding that $\Delta \mathrm{T}_{\mathrm{HP}}$ decreased as said above; and also higher heat transfer rate from the HTF would be achieved.

\subsection{Visual analysis}

With the aim to better understand how the melting process occurs inside the latent heat TES tanks, the charging process was video recorded. The footage allowed to qualitatively compare the five different thermal storage tanks. Fig. 10 shows all TES tanks at different charging stages, from completely solidified until totally molten. The different cases completed the loading process following the same pattern as shown by the PCM temperature analysis. Although, it has to be taking into account that the completing process time may differ from the temperature results. This happens because when controlling the process with temperature sensors you cannot ensure that the last portion of solid PCM is monitored by the installed sensors.

In all studied situations, due to the solid PCM higher density, the solid PCM sank down to the tank bottom. Fig. 10 corroborated what observed in the ST tank on the previous Section 3, n-octadecane started to melt from the HTF inlet side, being the last solid PCM to be molten at the tank region closer to HTF outlet. Although being true that in some pictures, such as HP16_A at 30 and $60 \mathrm{~min}$, one heat pipe has molten the PCM faster than the others, in general the process was uniform, and in each case more homogeneous than in the shell and tube TES tank (Fig. 10). As aforementioned, a homogeneous phase change avoids hot spot in the tank, being even more relevant in high temperature systems. Analysing Fig. 10 in detail, it can be observed that once the PCM around the $10 \mathrm{~mm}$ heat pipe is melted, the heat pipe heat release was focused on the tip. That effect was more prominent on the late stages of the HP10 processes, images (Fig. 10, HP10_A and HP10_B from 60 to $180 \mathrm{~min}$ ) show how the PCM was melted from the heat pipe tip towards the HTF manifold. As the small heat pipe could not release heat along their way to the tip, the inner working fluid travelled to the tip without yielding heat, where the condenser section is.

\subsection{Discharging process results}

The results obtained regarding discharging processes showed the same pattern. The fastest system to achieve the PCM solidification was the ST tank (129 min), followed by HP16_B (220 min), HP16_A (268 $\mathrm{min}$ ), HP10_B (380 $\mathrm{min}$ ) and HP10_A (501 $\mathrm{min})$. As the process was mainly driven by conduction it took longer than the charging one, as

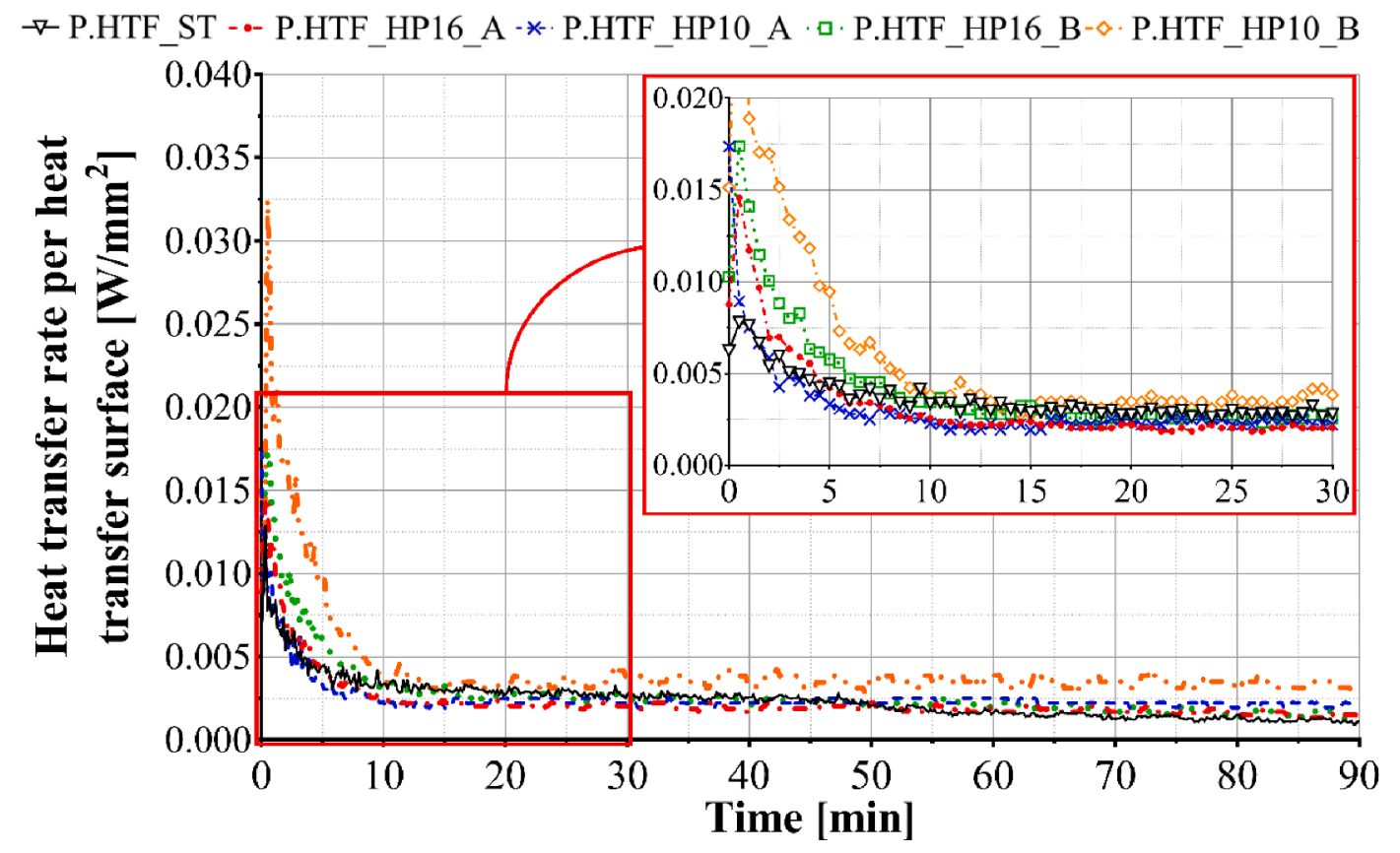

Fig. 9. Heat transfer rate per heat transfer surface area during the charging process. 


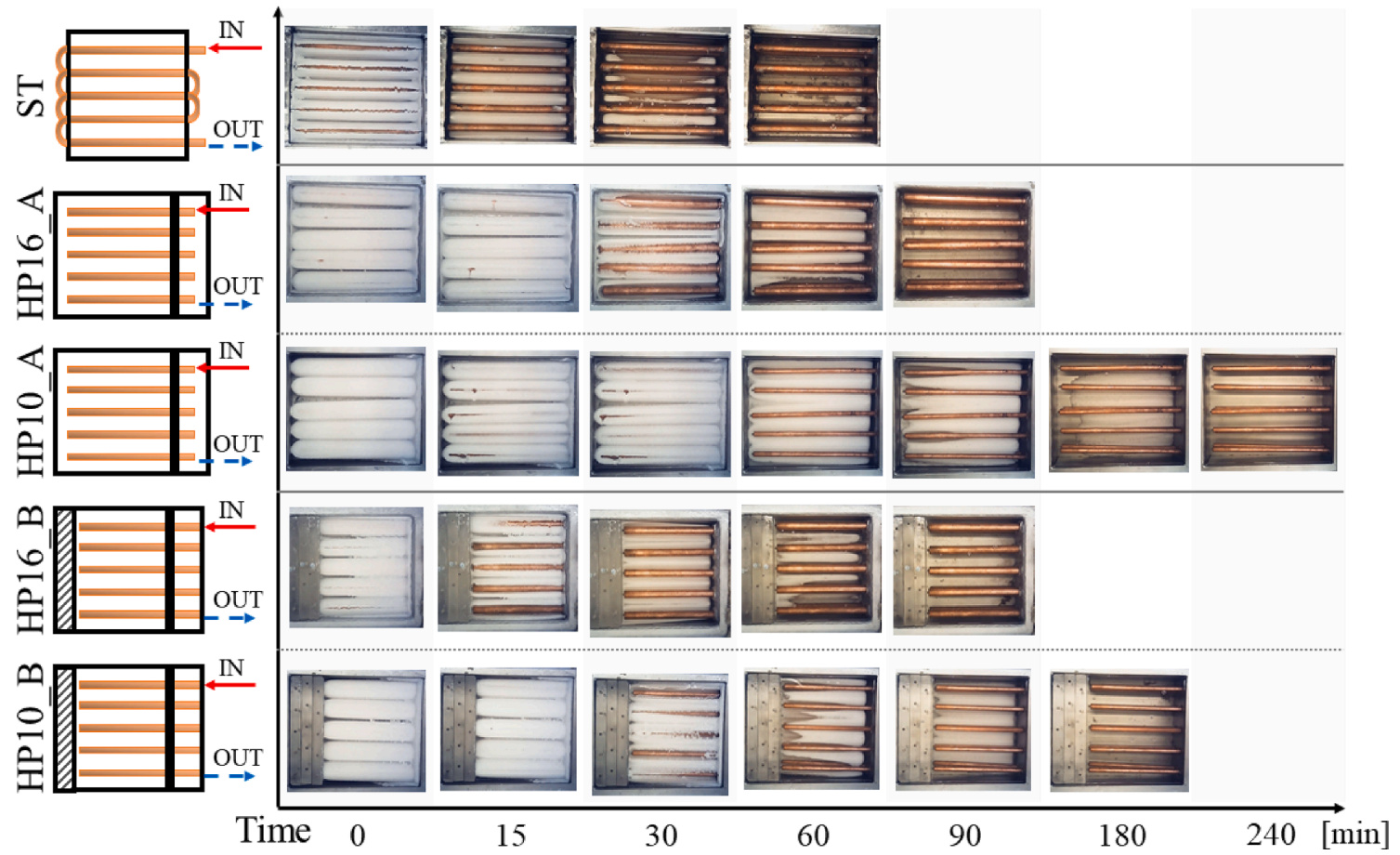

Fig. 10. Screenshots taken from the PCM melting videos. From top to bottom: shell and tubes, $16 \mathrm{~mm}$ heat pipes A, $10 \mathrm{~mm}$ heat pipes A, $16 \mathrm{~mm}$ heat pipes B, and 10 $\mathrm{mm}$ heat pipes $\mathrm{B}$.

stated in previous research [37]. Although the ST heat transfer rate was higher than the others, the difference between the ST and the heat pipes configurations in terms of power, was lower than along the charging process (Fig. 11). Once the PCM around the pipes, in each TES tank, solidifies, the PCM thermal conductivity took control of the process. Therefore, the natural convection induced in the PCM ST tank now did not boost the solidification process. When analysing the heat transfer rate per area, as observed during the charge, HP10_B showed higher rates (Fig. 12).

\section{Conclusions}

This paper experimentally investigates and compares the performance of conventional shell and tubes latent TES, and novel heat pipes latent TES configuration. In total five latent heat TES tank were tested, four of them consisting on heat pipes. The goal is to assess the benefits and drawbacks of using heat pipes instead of a HTF flowing through a common pipe, unlike previous research which compared heat pipes and metal rods. Earlier studies showed that heat pipes were a better option than using solid metal rods in every aspect, but the heat pipes benefit in

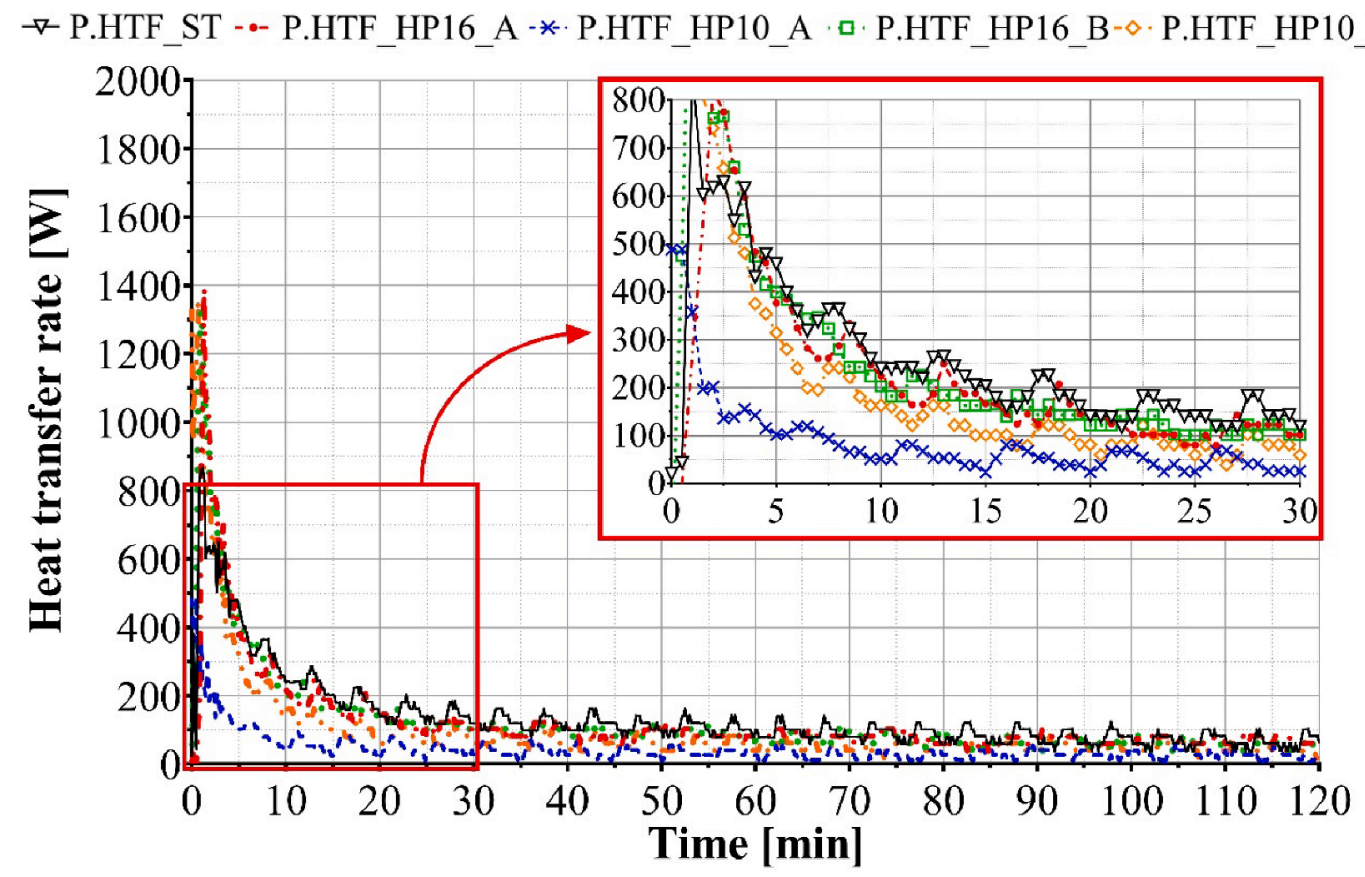

Fig. 11. Heat transfer rate comparison between the four different latent heat TES systems during the discharging process. 


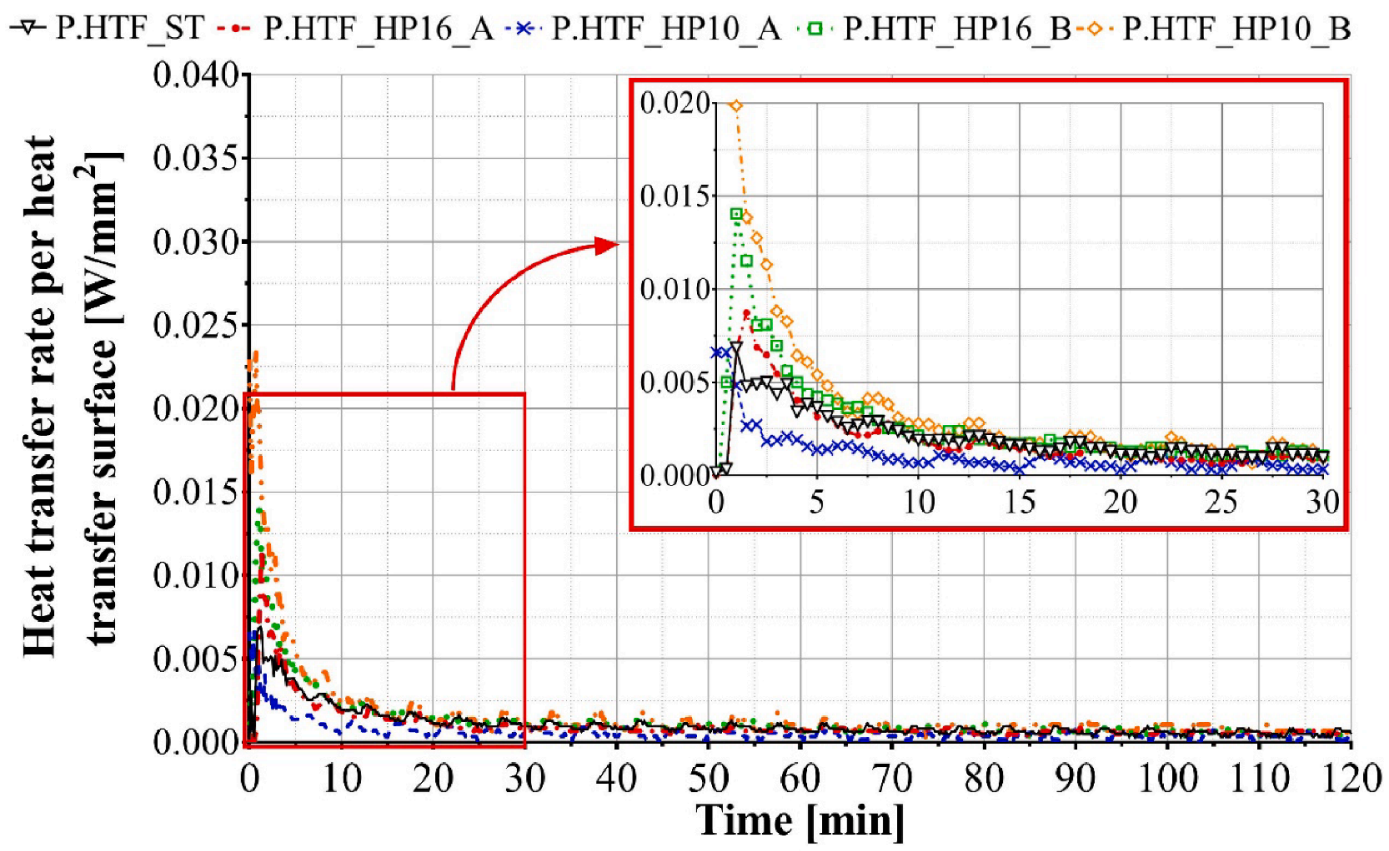

Fig. 12. Heat transfer rate per heat transfer surface area during the discharging process.

comparison with a shell and tubes system were not addressed. The results indicated that the use of heat pipes offered a loading process more uniform in terms of temperature but slower in terms of time. The ST latent TES tank temperature sensors showed almost 20 min gap between the first and the last sensor to finish the phase change process; while this gap was around $10 \mathrm{~min}$ in the heat pipes TES tanks. This fact was double checked with the video analysis of the processes. This effect can be useful to avoid hot zones, which could suffer a thermal shock, in the TES tank; being especially important when scaling up those systems at high temperatures.

The PCM conductivity took control on the heat pipe working cycle, because unlike a shell and tube system, the mass flow along heat pipes requires a temperature gradient between their tips. However, before that happened it was observed that heat pipes have the potential of delivering more heat than the shell and tubes. So, as long as the temperature gradient can be maintained as high as possible, heat pipes are a potential option to replace a shell and tubes system. This goal is difficult to achieve with low conductive PCMs, so an additional heat enhancement technique, such as fins or nano-particles, must be used.

Additionally, by modifying the heat pipe area inside the HTF manifold, the results proved that this characteristic was really relevant. The HP10_B average heat transfer rate along the first $30 \mathrm{~min}$ was around $30 \%$ higher than the HP10_B tank. However, doing the same comparison between HP16_B and HP16_A, that improvement was lower, around 5\%. Therefore, enough heat pipe evaporator section area must be in contact with the HTF to start and maintain the heat pipe circuit, but once the heat pipe can absorb heat from the HTF the heat conductivity within the PCM tank was the limiting factor. The latter statement implies that this feature is decisive at system design stage.

Also, this experimental assay gave proof that a bigger heat pipe does not necessarily mean better one. Smaller heat pipes (HP10_B) heat pipes were able to supply similar (but lower) amount of heat as the $16 \mathrm{~mm}$ ones (HP16_A and HP16_B); taking the first $30 \mathrm{~min}$, the average power was almost $350 \mathrm{~W}$ by the HP10_B, and around $380 \mathrm{~W}$ by HP16_A and $400 \mathrm{~W}$ by HP16_B. In terms of ratio between the power and heat transfer area, HP10_B achieved $60 \%$ better results than all the others latent TES tanks. Suggesting that it is better to increase the number of heat pipe instead of their size.

This study allowed to stand out the advantages of installing a heat pipe system as heat transfer technique instead of a conventional shell and tubes system, pointing out the leads to be pursued. Future research will be focused in comparing the effect of fin addition to the studied configurations. So, the extent to which the fins improve the different systems could be experimentally tested.

\section{CRediT authorship contribution statement}

Jose Miguel Maldonado: Conceptualization, Methodology, Formal analysis, Investigation, Writing - original draft, Writing - review \& editing, Visualization. David Verez: Methodology, Formal analysis, Investigation, Writing - original draft, Writing - review \& editing, Visualization. Alvaro de Gracia: Conceptualization, Methodology, Resources, Writing - review \& editing, Supervision, Project administration. Luisa F. Cabeza: Conceptualization, Methodology, Resources, Data curation, Writing - review \& editing, Supervision, Project administration, Funding acquisition.

\section{Declaration of Competing Interest}

The authors declare that they have no known competing financial interests or personal relationships that could have appeared to influence the work reported in this paper.

\section{Acknowledgments}

This work was partially funded by the Ministerio de Ciencia, Innovación y Universidades de España (RTI2018-093849-B-C31 MCIU/AEI/FEDER, UE) and by the Agencia Estatal de Investigación (AEI), of the Ministerio de Ciencia, Innovación y Universidades (RED2018-102431-T). José Miguel Maldonado would like to thank the Spanish Government for his research fellowship (BES-2016-076554). The authors would like to thank the Catalan Government for the quality accreditation given to their research group (2017 SGR 1537). GREiA is a certified TECNIO agent in the category of technology developers from the Government of Catalonia. This work is partially supported by ICREA under the ICREA Academia programme. 


\section{References}

[1] J.M. Maldonado, A. de Gracia, L.F. Cabeza, Systematic review on the use of heat pipes in latent heat thermal energy storage tanks, J. Energy Storage 32 (2020) 40, https://doi.org/10.1016/j.est.2020.101733.

[2] L.F. Cabeza, A. Castell, C. Barreneche, A. De Gracia, A.I. Fernández, Materials used as PCM in thermal energy storage in buildings: A review, Renew. Sustain. Energy Rev. 15 (2011) 1675-1695, https://doi.org/10.1016/j.rser.2010.11.018.

[3] P. Bose, V. Arasu, A review on thermal conductivity enhancement of paraf fin wax as latent heat energy storage material, Renew. Sustain. Energy Rev. 65 (2016) 81-100, https://doi.org/10.1016/j.rser.2016.06.071.

[4] L. Fan, J.M. Khodadadi, Thermal conductivity enhancement of phase change materials for thermal energy storage: A review, Renew. Sustain. Energy Rev. 15 (2011) 24-46, https://doi.org/10.1016/j.rser.2010.08.007.

[5] F. Agyenim, N. Hewitt, P. Eames, M. Smyth, A review of materials, heat transfer and phase change problem formulation for latent heat thermal energy storage systems (LHTESS), Renew. Sustain. Energy Rev. 14 (2010) 615-628, https://doi. org/10.1016/j.rser.2009.10.015.

[6] P. Di Giorgio, M. Iasiello, A. Viglione, M. Mameli, S. Filippeschi, P. Di Marco, A. Andreozzi, N. Bianco, Numerical Analysis of a Paraffin/Metal Foam Composite for Thermal Storage, J. Phys. Conf. Ser. 796 (2017), https://doi.org/10.1088/ 1742-6596/796/1/012032.

[7] M. Ghalambaz, J. Zhang, Conjugate solid-liquid phase change heat transfer in heatsink filled with phase change material-metal foam, Int. J. Heat Mass Transf. 146 (2020), 118832, https://doi.org/10.1016/j.ijheatmasstransfer.2019.118832.

[8] J. Gasia, L. Miró, L.F. Cabeza, Review on system and materials requirements for high temperature thermal energy storage. Part 1: General requirements, Renew. Sustain. Energy Rev. 75 (2017) 1320-1338, https://doi.org/10.1016/j. rser.2016.11.119.

[9] M.S. Naghavi, K.S. Ong, M. Mehrali, I.A. Badruddin, H.S.C. Metselaar, A state-ofthe-art review on hybrid heat pipe latent heat storage systems, Energy Convers Manage. 105 (2015) 1178-1204, https://doi.org/10.1016/j. enconman.2015.08.044.

[10] J. Gasia, L. Miró, L.F. Cabeza, Materials and system requirements of high temperature thermal energy storage systems: A review. Part 2: Thermal conductivity enhancement techniques, Renew. Sustain. Energy Rev. 60 (2016) 1584-1601, https://doi.org/10.1016/j.rser.2016.03.019.

[11] A. Faghri, Review and advances in heat pipe science and technology, J. Heat Transfer 134 (2012) 1-18, https://doi.org/10.1115/1.4007407.

[12] A. Faghri, Heat Pipe Science and Technology, 1st ed., Taylor \& Francis, Washington, D.C, 1995.

[13] G.Y. Eastman, The Heat Pipe, Sci. Am. 218 (1968) 38-46.

[14] A. Faghri, Heat Pipes: Review, Opportunities and Challenges, Front Heat Pipes 2014;5. https://doi.org/10.5098/fhp.5.1.

[15] M. Lacroix, M. Benmadda, Numercial simulatin of natural convection-dominated melting and solidification from a finned vertical wall, Numer Heat Transf, Part A 31 (1997) 71-86, https://doi.org/10.1080/10407789708914026.

[16] R.V. Seeniraj, R. Velraj, N.L. Narasimhan, Thermal analysis of a finned-tube LHTS module for a solar dynamic power system, Heat Mass Transf. 38 (2002) 409-417, https://doi.org/10.1007/s002310100268.

[17] M. Gharebaghi, I. Sezai, Enhancement of Heat Transfer in Latent Heat Storage Modules with Internal Fins, Numer Heat Transf 53 (2008) 749-765, https://doi. org/10.1080/10407780701715786.

[18] S.F. Hosseinizadeh, F.L. Tan, S.M. Moosania, Experimental and numerical studies on performance of PCM-based heat sink with different con fi gurations of internal fi ns q, Appl. Therm. Eng. 31 (2011) 3827-3838, https://doi.org/10.1016/j. applthermaleng.2011.07.031.

[19] C. Guo, W. Zhang, Numerical simulation and parametric study on new type of high temperature latent heat thermal energy storage system, Energy Convers Manag 49 (2008) 919-927, https://doi.org/10.1016/j.enconman.2007.10.025.
[20] Y.B. Tao, Y.L. He, Effects of natural convection on latent heat storage performance of salt in a horizontal concentric tube, Appl. Energy 143 (2015) 38-46, https://doi. org/10.1016/j.apenergy.2015.01.008.

[21] C.W. Robak, T.L. Bergman, A. Faghri, Enhancement of latent heat energy storage using embedded heat pipes, Int. J. Heat Mass Transf. 54 (2011) 3476-3484, https://doi.org/10.1016/j.ijheatmasstransfer.2011.03.038.

[22] N. Sharifi, T.L. Bergman, M.J. Allen, A. Faghri, Melting and solidification enhancement using a combined heat pipe, foil approach, Int. J. Heat Mass Transf. 78 (2014) 930-941, https://doi.org/10.1016/j.ijheatmasstransfer.2014.07.054.

[23] M.J. Allen, A. Faghri, T.L. Bergman, Robust heat transfer enhancement during melting and solidification of a PCM using a combined heat pipe-metal foam or foil configuration, in: ASME 2014 8th Int. Conf. Energy Sustain., Boston, U.S.A.: 2014, p. 1-12.

[24] M.J. Allen, N. Sharifi, A. Faghri, T.L. Bergman, Effect of inclination angle during melting and solidification of a phase change material using a combined heat pipemetal foam or foil configuration, Int. J. Heat Mass Transf. 80 (2015) 767-780, https://doi.org/10.1115/1.4029970.

[25] S. Motahar, R. Khodabandeh, Experimental study on the melting and solidification of a phase change material enhanced by heat pipe, Int Commun Heat Mass Transf 73 (2016) 1-6, https://doi.org/10.1016/j.icheatmasstransfer.2016.02.012.

[26] S. Tiari, S. Qiu, M. Mahdavi, Numerical study of finned heat pipe-assisted thermal energy storage system with high temperature phase change material, Energy Convers Manag 89 (2015) 833-842, https://doi.org/10.1016/j. enconman.2014.10.053.

[27] S. Tiari, S. Qiu, Three-dimensional simulation of high temperature latent heat thermal energy storage system assisted by finned heat pipes, Energy Convers Manag 105 (2015) 260-271, https://doi.org/10.1016/j.enconman.2015.08.004.

[28] S. Tiari, M. Mahdavi, V. Thakore, S. Joseph, Thermal analysis of a hightemperature heat pipe-assisted thermal energy storage system with nano-enhanced phase change material, in: ASME Int Mech Eng Congr Expo Proc 2018;6B-2018: 1-10. https://doi.org/10.1115/IMECE2018-86481.

[29] C. Pan, N. Vermaak, C. Romero, S. Neti, S. Hoenig, C.H. Chen, Efficient optimization of a longitudinal finned heat pipe structure for a latent thermal energy storage system, Energy Convers Manag 153 (2017) 93-105, https://doi. org/10.1016/j.enconman.2017.09.064.

[30] C. Pan, N. Vermaak, C. Romero, S. Neti, S. Hoenig, C.H. Chen, et al., Cost estimation and sensitivity analysis of a latent thermal energy storage system for supplementary cooling of air cooled condensers, Appl. Energy 224 (2018) 52-68, https://doi.org/10.1016/j.apenergy.2018.04.080.

[31] S. Lohrasbi, S.Z. Miry, M. Gorji-Bandpy, D.D. Ganji, Performance enhancement of finned heat pipe assisted latent heat thermal energy storage system in the presence of nano-enhanced $\mathrm{H} 2 \mathrm{O}$ as phase change material, Int. J. Hydrogen Energy 42 (2017) 6526-6546, https://doi.org/10.1016/j.ijhydene.2017.01.045.

[32] S. Lohrasbi, M. Gorji-Bandpy, D.D. Ganji, Thermal penetration depth enhancement in latent heat thermal energy storage system in the presence of heat pipe based on both charging and discharging processes, Energy Convers Manag 148 (2017) 646-667, https://doi.org/10.1016/j.enconman.2017.06.034.

[33] M. Lacroix, Numerical simulation of a shell-and-tube latent heat thermal energy storage unit, Sol. Energy 50 (1993) 357-367, https://doi.org/10.1016/0038-092X (93)90029-N.

[34] H.A. Adine, H. El Qarnia, Numerical analysis of the thermal behaviour of a shelland-tube heat storage unit using phase change materials, Appl. Math. Model. 33 (2009) 2132-2144, https://doi.org/10.1016/j.apm.2008.05.016.

[35] D. Kukulka, Thermodynamic and Transport Properties of Pure and Saline Water. State University of New York at Buffalo, USA, 1981.

[36] J. Holman, Experimental Methods for Engineers. 8th ed. New York: 2012.

[37] J. Gasia, J.M. Maldonado, F. Galati, M. De Simone, L.F. Cabeza, Experimental evaluation of the use of fins and metal wool as heat transfer enhancement techniques in a latent heat thermal energy storage system, Energy Convers Manag 184 (2019) 530-538, https://doi.org/10.1016/j.enconman.2019.01.085. 